\title{
Unsur Budaya Dalam Cerita Film Cakra Buana Karya Sutradara Massimo Burhanuddin
}

\author{
Revi Dwiyanti, Agus Suherman \\ Universitas Pendidikan Indonesia \\ revidwiyanti@upi.edu
}

\begin{abstract}
Sejarah Artikel: Diterima (28 Juni 2019); Diperbaiki (13 Agustus 2019); Disetujui (6 Oktober 2019); Pusblished (31 Oktober 2019)

Bagaimana mengutip artikel ini (dalam gaya APA): Dwiyanti, R., Suherman, A. (2019). Unsur

Budaya Dalam Cerita Film Cakra Buana Karya Sutradara Massimo Burhanuddin. Lokabasa, 10(2). 204-213 doi: 10.17509/jlb.v10i2.21361
\end{abstract}

Abstrak: Penelitian ini dilatarbelakangi oleh kurangnya penelitian tentang perfilman yang menggunakan bahasa dan latar budaya Sunda. Penelitian ini bertujuan untuk mendeskripsikan unsur budaya yang ada dalam cerita film Cakra Buana. Metode yang digunakan dalam penelitian ini adalah deskriptif analisis dengan teknik studi dokumen yang berupa karya seni. Sumber data dalam penelitian ini yaitu cerita film Cakra Buana karya sutradara Massimo Burhanuddin. Hasil penelitian meliputi 7 unsur budaya, diantaranya: bahasa, film ini menggunakan bahasa Sunda serta menggunakan undak usuk basa, sistem pengetahuan dibagi berdasarkan pengetahuan tentang alam dan sosial, organisasi sosial meliputi sistem pemerintahan, cara mengganti pemimpin dan sebutan kekerabatan, sistem teknologi diantaranya perkakas, makanan, pakaian, rumah dan alat transportasi, sistem mata pencahariannya yaitu bercocok tanam, sistem religinya masih ada pengaruh dari ajaran Hindu dan Buddha karena menggunakan kata "Sang Hyang" dalam menyebutkan nama Tuhan, dan kesenian dalam film ini ada 2 yaitu seni musik dan seni gerak.

Kata Kunci: film; unsur budaya

\section{Cultural Elements in The Story of Cakra Buana Movie by Director Massimo Burhanuddin}

Abstract: This research is motivated by the lack of research on film that uses Sundanese language and cultural settings. This study aims to describe the cultural elements that exist in the Cakra Buana film story. The method used in this research is descriptive analysis with document study techniques in the form of artwork. The data source in this study is the story of the film Cakra Buana by director Massimo Burhanuddin. The results of the study include 7 cultural elements, including: language, this film uses Sundanese language and undak usuk basa, knowledge systems are divided based on knowledge about nature and social, social organizations include government systems, how to replace leaders and designations of kinship, technological systems including tools, food, clothing, houses and means of transportation, the livelihood system that is farming, the religious system is still influenced by Hinduism and Buddhism because it uses the word "Sang Hyang" in mentioning the name of God, and there are 2 arts in this film namely music and art motion (traditional dance).

Keywords: film; cultural elements 


\section{PENDAHULUAN}

Budaya merupakan identitas bangsa. Manusia dan budaya memiliki hubungan yang erat karena manusia adalah bagian dari budaya itu sendiri. Hampir semua tindakan manusia dapat dikategorian sebagai produk kebudayaan. Kebudayaan di Indonesia sangat banyak dan tentu saja masing-masing daerah memiliki karakteristik kabudayaannya sendiri. Budaya bagi masyarakat merupakan hal yang penting dalam kehidupan karena budaya merupakan identitas. Selain identitas, budaya juga merupakan sistem tata kehidupan atau seperti blueprint (cetak biru) yang dijadikan design for living (desain untuk kehidupan) dalam melakukan suatu perilaku. Williams (dalam Triyanto, 2014, hlm. 35), menyatakan bahwa budaya adalah keseluruhan cara hidup, budaya merupakan makna dan nilai kehidupan seharihari yang merupakan bagian dari totalitas ekspresif hubungan-hubungan sosial. Kebudayaan sangat erat dengan kehidupan sehari-hari. Dengan demikian, banyak cara untuk mempresentasikan budaya.

Budaya adalah semua sistem gagasan, tindakan dan hasil karya manusia dalam kehidupan masyarakat yang menjadi hak milik dengan cara belajar (Koetjaraningrat 2009, hlm. 144). Pengertian yang menunjukkan bahwa kebudayaan merupakan "tindakan budaya" adalah semua tindakan harus dibiasakan oleh manusia dengan cara dipelajari (learned behavior). Hal tersebut juga dijelaskan oleh beberapa antropolog, di antaranya C. Wissler, C. Kluckhohn, A. Davis atau A. Hoebel (Koentjaraningrat, 2009, hlm. 145).

Kebudayaan di Indonesia yang begitu banyak dimanfaatkan untuk direpresentasikan dalam bentuk karya seni, salah satunya adalah film. Eddy D. Iskandar, dalam diskusi bertajuk "Peran bahasa di alam semesta Film Indonesia" menyatakan bahwa penggunaan latar belakang budaya Sunda dalam film masih sangat sedikit, dan bisa dikatakan belum ada. Banyak karya sastra yang bisa ditranformasikan ke dalam film tetapi hambatannya yaitu dari bahasanya, karena tidak semua produser Indonesia bisa memahami bahasa daerah/Sunda. Namun, penggunaan film berlatar belakang budaya Sunda bukan artinya harus menggunakan bahasa Sunda, tetapi bisa diambil berdasarkan inspirasi kisah atau cerita sastra Sunda (www.beritasatu.com).

Film yang diteliti dalam penelitian ini yaitu film Cakra Buana yang disutradarai oleh Massimo Burhanuddin, durasinya berlangsung 84 menit. Naskah skenario ditulis oleh Massimo Burhanuddin dan Getar Jagatraya. Film ini diproduksi pada tahun 2015 dan telah ditayangkan di Bali dalam rangka Balinale (Bali International Film Festival). Film Cakra Buana merupakan film yang menggunakan bahasa dan latar budaya Sunda.

Pentingnya dilaksanakan penelitian ini agar menambah pengetahuan dan wawasan mengenai kebudayaan, terutama di dunia perfilman yang jarang menggunakan latar belakang budaya dan bahasa Sunda, yang menurut Suherman (2018, hlm. 470; 2019, hlm. 264) merupakan kegiatan literasi budaya. Selain itu, penelitian ini diharapkan menjadi salah satu jalan pembuka untuk memperluas penelitian mengenai filmfilm Sunda, terutama yang membahas unsur budayanya.

Penelitian sebelumnya yang sejenis dengan penelitian ini dalam bentuk skripsi lebih banyak diterapkan pada karya sastra, diantaranya: "Struktur Intrinsik jeung Unsur Budaya dina Novél Tanjeur $\mathrm{Na}$ Juritan Jaya di Buana Karangan Yoséph Iskandar Pikeun Bahan Pangajaran Aprésiasi Sastra di SMA" oleh Winda Rohayani (2013) dan "Analisis Struktur jeung Ajén Budaya dina Novél Baruang $k a$ nu Ngarora 
Karya D.K Ardiwinata" oleh Thaifur Abu Yazid, (2015), ada juga yang diterapkan pada film, yaitu"Analisis Unsur-Unsur Budaya dalam Film Comme Un Chef" oleh Syifa Nudiya Fauziyah, (2015).

Persamaan penelitian ini dengan penelitian sebelumnya adalah tentang pembahasan mengenai unsur budaya tetapi diterapkan pada objek penelitian yang berbeda. Dengan demikian, penelitian tentang unsur-unsur budaya dalam cerita film Cakra Buana perlu dilakukan.

\section{METODE}

Metode penelitian adalah cara yang digunakan dalam mengumpulkan data. Metode yang digunakan adalah metode kualitatif. Penelitian kualitatif memberikan perhatian kepada data alamiah, data yang berhubungan dengan konteks kenyataannya. Metode dalam penelitian ini adalah metode deskriptif analisis. Menurut Ratna (2011, kc. 53), metode deskriptif analisis adalah metode penelitian dengan cara mendeskripsikan fakta-fakta dalamsumber data, tahap berikutnya yaitumenganalisis. Kesimpulannya, metode deskriptif analisis memusatkan perhatian pada masalah, kemudian hasil penelitian yang sudah dianalisis selanjutnya diambil kesimpulannya.

Sumber data dalam penelitian ini adalah cerita film Cakra Buanayang disutradarai oleh Massimo Burhanuddin. Durasi film adalah 84 menit. Film ini menceritakan kehidupan masyarakat pertanian dan semua konflik yang timbul karena masalah kepemimpinan. Bahasa yang digunakan yaitu bahasa Sunda, penyampaian dialognya dengan cara dinyanyikan. Selain penggunaan bahasanya, film ini juga mengandung unsurunsur budaya Sunda.Teknik yang digunakan dalam penelitian ini adalah studi dokumen. Sesuai dengan yang dijelaskan oleh Sugiyono (2013, kc. 240) bahwa dokumentasi dapat berupa karya seni seperti gambar, patung, film, dan lain-lain. Sedangkan teknik analisis data yang digunakan yaitu analisis isi (content analysis)yang sering digunakan dalam data penelitian kualitatif. Analisis isi muncul dari anggapan dasarilmu-ilmu sosial bahwa studi mengenai proses dan isi komunikasi adalah dasar dari ilmuilmu sosial (Bungin, 2015, hlm. 84).Instrumen yang digunakan dalam penelitian ini yaitu tabel untuk menganalisis unsur budaya dalam film Cakra Buana.

\section{HASIL DAN PEMBAHASAN}

Film adalah sebuah karya cipta seni dan budaya yang memanfaatkan media komunikasi massa pandangdengar. Film di sesuai dengan prinsip sinematografi dengan cara objek direkam pada pita seluloid, pita video, dan temuan teknologi lainnya (digitalisasi) dalam segala bentuk dan ukuran. Film atau gambar hidup adalah gambar yang diproyeksikan dalam framedari lensa proyektor mekanis ke dalam layar atau bidang putih yang dapat dipantulkan kembali gambar-gambar tersebut (Isnendes, 2018, hlm. 34).

Menurut beberapa teori film, film merupakan arsip sosial yang menyimpan jiwa jaman (zeitgeist) masyarakat pada saat itu. Slegfried Kracauer (Imanjaya, 2006, hlm. 30), menyatakan bahwa biasanya dapat dilihat apabila teknik, isi cerita dan perkembangan film satu bangsa hanya dapat dipahami secara keseluruhan dalam hubungannya dengan pola psikologis aktual bangsa itu sendiri. Artinya, pertumbuhan film Indonesia hanya dapat dipahami jika latar belakang terkait dan sosial dari perkembangan budaya bangsa itu sendiri.

Koentjaraningrat (2009, hlm. 165) menyatakan bahwa ada tujuh unsur kebudayaan, yaitu bahasa, sistem pengetahuan, organisasi sosial, sistem teknologi, sistem mata pencaharian, sistem religi dan kesenian. 


\section{Bahasa}

Bahasa yang digunakan dalam film itu sepenuhnya menggunakan bahasa Sunda. Bahasa Sunda memiliki Undak Usuk Basa yang biasa dipakai dalam kehidupan sehari-hari. Dalam film ini menggunakan bahasa Sunda loma dan lemes. Dialognya menggunakan bahasa yang sering dipakai dalam kehidupan sehari-hari karena mudah dimengerti.

Dialog yang menggunakan bahasa lemes terdapat dalam salah satu adegan ketika Laksmi sedang mempersiapkan makanan di dapur.

Laksmi : "Sangu pulen anyar nyait

Réncangna saaya-aya

Lalab rumbah anyar ngundeur sambel tarasi

Ngahudang sari

Peda beureum

Kéngéng meuleum

Matak ni'mat hoyong mindo

Abdi pak-pik-pek,

najan nu katénjo ukur poék

Tapi létah mah bisa ngarasa

Sukuran kana ni'mat ti Gusti."

Laksmi: "Nasi pulen baru diangkat

Lauk-pauk seadanya

Lalapan baru dipetik, sambal terasi

Membangkitkan nafsu makan

Ikan peda merah, sudah dibakar

Membuat nikmat, ingin menambah (makan)

Saya sibuk menyiapkan makanan, meskipun yang terlihat hanya gelap

Tapi lidah tetap bisa merasakan Bersyukur atas nikmat dari Tuhan"

\section{Sistem Pengetahuan}

Sistem pengetahuan meliputi alam sekitar yang ada dalam film ini yaitu pesawahan, gunung, sungai, dan hutan.
Pesawahan merupakan tempat warga untuk melakukan pekerjaan utamanya yaitu bercocok tanam. Ada pula sungai, hutan dan gunung yang ditampilkan secara singkat dan tidak disebutkan nama tempat tersebut secara detail. Sementara pengetahuan tentang alam sekitar yang bersifat religi ada di awal film ketika warga sedang bertani sembari mengucap syukur kepada Tuhan atas apa yang diberikan menceritakan warga yang kemudian pertanian berkat Tuhan untuk semua yang diberikan melewati alam yang dapat dimanfaatkan menjadi berbagai macam olahan makanan, dan lain-lain.

\section{Warga : "Pun sapun ka HyangAgung Nuhun mangrébu nuhun \\ Kana pangaping pangjaring \\ Abdi seja sujud sukur \\ Kana ni'mat nu tos \\ Dilungsurkeun \\ Nu pangrupi dangdaunan \\ sareng bungbuahan \\ Nu ayeuna janten kaolahan \\ Nu kacida raosna"}

Warga : "Salam kepada Hyang Agung

Terima kasih beribu terima

kasih

Atas bimbingannya

Saya seraya sujud syukur

diberikan

Atas nikmat yang telah

Yang berupa daun-daun

dan buah-buahan

Yang sekarang menjadi olahan

Yang begitu nikmatnya"

Selain itu, sistem pengetahuan yang memiliki hubungan dengan religi ada dalam adeganWeh yang sedang sakit keras, lalu melihat keadaan desa yang mongering karena musim kemarau panjang. Weh mendoakan desa dan anaknya yang menggantikannya menjadi ketua adat sembari mengangkat sebuah guci kecil dan menghadap ke jendela. 
Pengetahuan tentang alam flora nampak secara jelas dalam film ini, karena sangat erat kaitannya dengan pekerjaan utama adalah bercocok tanam. Ada beberapa adegan yang menunjukkan bahwa alam flora dimanfaatkan untuk kebutuhan hidup sehari-hari. Selain itu film ini juga menunjukkan bagaimana manusia memanfaatkan tanaman menjadi obat-obatan herbal. Adegannya pada saat Weh sakit keras dan ia diberi obat oleh dukun, meskipun tidak menyebutkan nama tanaman atau daun tersebut.

Pengetahuan tentang alam fauna untuk kehidupan sehari-hari tidak ditampilkan dalam film. Meskipun dalam kegiatan pertanian ada ngawulukuyan biasanya menggunakan sapi atau kerbau tetapi tidak diperlihatkan dalam film.

Bahan mentah yang sering digunakan dalam film ini yaitu penggunaan bahan mentah yang dimanfaatkan dari alam sekitar. Warga memiliki pengetahuan tentang teknologi yang memanfaatkan alam, seperti memanfaatkan hasil tani untuk kebutuhan sehari-hari. Selain itu, tanaman juga digunakan sebagai bahan untuk membuat makanan, juga dapat digunakan sebagai bahan obat. Selain sebagai makanan, bahan seperti bambu yang digunakan oleh Cakra dan warga dalam membuat pipa air.

Pengetahuan tentang tubuh manusia dalam film ini terlihat adanya dukun yang memberi pengobatan untuk Weh yang sedang sakit keras. Cara mengobatinya adalah dengan menggunakan tanaman sebagai obat herbal, semua bahan dicampur dan kemudian ditempatkan dalam guci kecil. Dikarenakan dukun ini dapat mengobati penyakit yang diderita Weh, hal ini tentunya menunjukkan bahwa dukun mengetahui bagian-bagian tubuh manusia, dan memiliki pengetahuan tentang karakteristik tubuh manusia. Meskipun film ditunjukkan bahwa obat yang diberikan oleh dukun tersebut merupakan racun yang dibuat oleh Galuh agar penyakit Weh semakin parah.

Beberapa pengetahuan tentang kesopanan dalam bergaul dengan sesama manusia yaitu terlihat pada saat warga saling membantu dalam menjalankan rencana Cakra yaitu membuat pipa air. Cakra memberikan intruksi dan arahan kepada warga kemudian warga bekerja sama dalam membuat pipa tersebut. Dimulai dari memotong bambu lalu diikat dengan ijuk.

Cakra : "Teukteuk awina.

Cocog bukuna

Sambungkeun congona

Bungkus ku injuk

Heug kadé katincak

Tah ieu kuluwung jalan keur cai"

\section{Warga : "Digawé babarengan \\ Ieu kuluwung \\ Keur jalan cai \\ Cai walungan \\ Ngamalir ka sawah \\ Tah ieu hiji tarékah \\ Nyanghareupan katiga \\ panjang"}

Cakra: "Potong bambunya

Cocokkan bambunya

Sambungkan ujungnya

Bungkus dengan ijuk

Hati-hati terinjak

Inilah pipa untuk aliran air

\section{Warga : "Bekerja bersama-sama Ini pipa untuk aliran air Air sungai mengalir ke sawah Ini adalah suatu upaya Menghadapi kemarau panjang"}

Selain pengetahuan mengenai sopan santun dalam bergaul dengan sesama manusia, ada pula pengetahuan mengenai adat-istiadatnya, yaitu ketika Weh selaku ketua adat sudah tidak sanggup untuk memimpin desa, maka 
harus segera ada penggantinya. Warga menyelenggarakan perkumpulan untuk membicarakan pengganti ketua adat. Warga mempunyai dua pilihan, yaitu Cakra atau Galuh. Warga yang memilih Galuhberpendapat bahwa dia adalah wakil dari Weh, sehingga Galuh dianggap mampu memimpin desa karena ia mengetahui apa saja yang berkenaan dengan desa ini. Ada juga warga yang lebih setuju Cakra menjadi ketua, karena Cakra merupakan anak kandung lelaki dari Weh. Berdasarkan hukum adat, tentunya yang bisa menggantikan posisi ketua adat yaitu anak kandungnya. Warga yang memilih Cakra untuk menjadi ketua adat memiliki pengetahuan tentang hukum adat yang ada di desa, bahwa yang seharusnya menjadi ketua adat yaitu anak kandung Weh, Cakra.

Konsep ruang dan waktu tidak ditampilkan dengan jelas dalam film ini. Adegan yang menunjukkan adanya sistem untuk mengukur waktu, ketika Weh datang ke sawah menghampiri warga yang sedang bertani, lalu memberi tahu bahwa desa akan segera menghadapi musim kemarau panjang.

\section{Wéh : "Rahayat nu dipicinta}

Ngolébat dina implengan

Saméméh panon poé surup

Aya totondén goréng

Diharéwoskeun kudangdaunan

Baris datang usum katiga

Tumiba ka lembur urang

Tapi tong salempang

Hayu urang tungkulan

babarengan"

Weh: "Rakyat yang (saya) cintai

Sekilas terbayang dalam ingatan

Sebelum matahari terbenam

Ada pertanda buruk

Dibisikkan oleh dedaunan

Akan datang musim kemarau

Menimpa kepada desa kita

Tapi jangan khawatir

Mari kita atasi bersama-sama"
Dialog di atas menunjukkan bahwa Weh mengukur datangnya musim kemarau panjang dengan kalimat "diharéwoskeun ku dangdaunan" (dibisikkan oleh dedaunan), artinya tumbuhan yang ada di desa akan semakin mengering, maka dari itu harus segera ada solusi agar desa dapat berhasil melewati musim kemarau panjang.

\section{Organisasi Sosial}

Organisasi sosial meliputi sistem pemerintahan, suksesi kepemimpinan dan silsilah keluarga. Sistem pemerintahan dalam film ini terlihat sederhana, suksesi kepemimpinannya pun dilakukan secara turun temurun. Sedangkan silsilah keluarganya yaitu ada yang menjadi ayah, ibu, anak, kakak dan adik.

Jika mengacu pada organisasi sosial masyarakat Kanekes, dibagi menjadi tiga wilayah, yaitu (1) wilayah Tangtu yang dipimpin oleh puun,(2) wilayah Panamping yang dipimpin oleh kokolot, dan (3) wilayah Dangka yang merupakan wilayah terluar (Ekadjati, 2014, hlm. 66), organisasi sosial yang ada dalam film ini ditampilkan jauh lebih sederhana.

Menurut organisasi sosial masyarakat Kanekes, puun memiliki beberapa wakil yang memiliki tugas berbeda-beda. Pertama, ada yang disebut seurat, yang bertanggung jawab untuk merawat huma sérang, sedangkan wakil utamanya menghubungkan antara puun dan masyarakat. Jabatan dibawah seuratada yang disebut dengan barésan, yang termasuk anggota sidang kapuunan dan mempunyai tanggung jawab dalam masalah keamanan (Ekadjati, 2014, hlm. 69). Sementara di film ini, ketua juga memiliki wakil, tetapi tidak kompleks dan lengkap seperti organisasi sosial masyarakat Sunda di Kanekes. Ketua memiliki satu wakil utama yang bertugas membantu ketua dalam segala urusan di desa dan menjadi penghubung antara 
ketua dan masyarakatnya. Tugas wakil ini hampir sama dengan tugas seurat di organisasi sosial masyarakat Sunda di Kanekes.

Warga melakukan perintah yang diberikan oleh ketua adat, dapat diperintahkan secara langsung atau melalui wakil ketua adat. Warga mempunyai kewajiban untuk menjaga desa, memanfaatkan alam untuk kebutuhan sehari-hari secara bijaksana. Warga juga mempunyai hak dalam memilih pemimpin.

Peranpuun di masyarakat Kanekes berlaku secara turun-temurun, jangka waktu jabatannya tidak tentu, bisa sampai puun tersebut meninggal dunia atau menyerahkan jabatannya kepada orang lain (Ekadjati, 2014, hlm. 69). Demikian juga yang terlihat dalam film ini, pergantian pemimpin dilakukan secara turun-temurun yaitu dari ayah (Weh) kepada anaknya (Cakra). Jabatan Weh sebagai ketua adat diganti karena Weh sakit keras dan tidak sanggup lagi memimpin desa.

\section{Sistem Teknologi}

Sistem teknologi, meliputi peralatan produksi, senjata, wadah, makanan, pakaian, rumah, dan transportasi. Alat produksi dalam film Cakra Buana yaitu ada 2 peralatan potong. Peralatan potong yang digunakan dalam film yaitu ada golok dan arit. Golok digunakan untuk memotong bambu ketika akan membuat pipa air, sedangkan arit digunakan untuk megambil padi atau mencabut rumput. Peralatan pertanian yaitu ada dudukuy yang terbuat dari bambu yang dianyam. Fungsinya yaitu sebagai penutup kepala. Ada pula nyiru yang digunakan ketika membersihkan beras. Peralatan produksi yang banyak digunakan dalam film ini yaitu peralatan rumah tangga. Terdapat 17 peralatan rumah tangga yang mempunyai bahan dan fungsi yang berbeda-beda. Pipiti dan tolombong yaitu wadah yang terbuat dari bambu yang dianyam. Pipiti mempunyai fungsi sebagai wadah nasi dan laukpauknya. Peralatan rumah tangga yang terbuat dari kayu ada cukil, talenan, susuk, dan songsong. Ada pula yang terbuat dari kaleng atau aluminium, batu atau tanah liat.

Terdapat 2 senjata yang digunakan yaitu golok dan pisau, yang sebenarnya pula termasuk dalam peralatan biasa. Golok digunakan sebagai senjata karena dalam adegan yang berlatar halaman rumah Cakra, Birawa menggunakan golok sebagai senjata untuk melawan Cakra. Golok ini biasanya digunakan oleh Birawa dan diikat pada pinggangnya. Ada juga wadah yang digunakan dalam film ini yaitu 2 wadah yang terbuat dari bambu, dan 4 wadah yang terbuat dari kaleng. Wadah yang terbuat dari bambu biasanya digunakan sebagai wadah makanan seperti pipiti, sedangkan tolombong digunakan sebagai wadah menyimpan pakaian yang akan dicuci. Selain itu pula ada 4 wadah yang terbuat dari kaleng, biasanya digunakan untuk makanan dan minuman, yaitu sangku, rantang, teko, dan cangkir.

Pengetahuan mengenai makanan juga hasil dari pemanfaatan alam, dalam mengolah makanan masih menggunakan alat dan cara yang tradisional. Sedangkan yang berkaitan dengan cara berpakaian, terlihat sederhana. Laki-laki memakai iket, pangsi, kampret dan sarung, sedangkan perempuan menggunakan baju dan rok samping. Ada beberapa rumah yang digunakan, yaitu rumah panggung, balai desa, lumbung dan gubuk Berdasarkan sudut pandang pemakaiannya, ada gubuk dan rumah tetap. Gubuk yang dimaksud adalah saung yang berada di tengah sawah. Sedangkan rumah tetap yaitu rumah Cakra yang bentuknya berupa rumah panggung terbuat dari kayu dan bambu. Ruangannya terbagi dua luar dan dalam. Setiap ruangannya dibatasi tembok bambu, pintunya terbuat dari 
kayu dan ditutupi oleh gorden, atapnya menggunakan ijuk.

Dilihat berdasarkan fungsi socialnya, terdapat rumah yang digunakan untuk kegiatan umum yaitu balai desa. Balai merupakan tempat yang lokasinya berada di tengah desa. Lalu ada satu bangunan yang dipakai untuk menyimpan padi yaitu lumbung padi). Sedangkan rumah yang fungsinya untuk kegiatan keagamaan atau tempat suci tidak diperlihatkan dalam film. Alat transportasi pula tidak muncul dalam film ini karena teknologi ini masih sederhana, transportasi nu digunakeun aya hiji nyaéta rakit.

\section{Sistem Mata Pencaharian}

Pekerjaan utama dalam film ini adalah pertanian atau bercocok tanam. Pertanian adalah sumber utama untuk memenuhi kebutuhan sehari-hari, tapi proses pertanian yang ditampilkan di film ini tidak diperlihatkan secara keseluruhan.

Hasil pertanian digunakan untuk memenuhi kebutuhan sehari-hari. Sawah digarap dan dimanfaatkan oleh warga itu sendiri. Alat pertanian yang digunakan masih tradisional. Proses tani yang ada dalam film tidak seluruhnya diperlihatkan, hanya beberapa bagian saja. Di awal film menunjukkan warga yang sedang macul, ngagebug pare dan ngarit. Di tengah cerita, ditunjukkan sekilas warga yang sedang ngirab sawan yaitu membersihkan sawah dari sampah dedaunan atau rumput yang ada di sekitar padi. Hasil tani lalu disimpan di leuit yang letaknya dekat dengan rumah Cakra.

\section{Sistem Religi}

Dalam film ini bisa disebut bahwa kepercayaan yang dianut ada pengaruh dari Hindu dan Buddha karena masih menggunakan konsep Hyang, yaitu Hyang Agung, Hyang Widi yang sama artinya dengan Sang Hyang Keresa atau
Sang Hyang Tunggal. Sedangkan aktivitas religi yang ada dalam film terlihat ketika Weh sedang mendoakan Cakra di kamarnya sembari mengangkat guci kecil, serta saat warga sedang mengucap syukur kepada Hyang Agung.

Hyang Agung ada dalam kekuasaan tertinggi, sama dengan Sang Hyang Keresa atau Sang Hyang Tunggal dalam kepercayaan masyarakat Sunda di Kanekes. Sang Hyang Tunggal melahirkan 7 batara yaitu Batara Cikal, Batara Kala, Batara Brahma, Batara Wiswara, Batara Wisnu, Batara Patanjala, dan Batara Mahadewa (Sumardjo, 2011, hlm. 21). Selain Hyang Agung, ada sebutan lain yaitu Sang Hyang Widi.

Selain itu, ada adegan yang mengucap Hyang Widi dan istilah "kama datu" ketika Cakra akan dipasung di suatu tempat yang tidak disebutkan namanya. Kama datu merupakan istilah kosmologi Buddha yang artinya berkenaan dengan kehidupan manusia paling rendah yaitu ranah hawa nafsu (Halim, 2017, hlm. 173).

Kegiatan keagamaan yang berkaitan dengan upacara keagamaan tidak diperlihatkan di film ini. Sementara kegiatan keagamaan yang berhubungan dengan emosi keagamaan adalah ketika Weh sedang sakit keras lalu ia mendoakan Cakra dan desanya agar dapat berhasil memimpin desa dengan baik.

\section{Kesenian}

Kesenian yang ada dalam film ini yaitu seni musik yang termasuk dalam musik instrumental, yaitu karinding. Karinding merupakan alat musik tradisional Sunda yang terbuat dari bambu. Karinding biasanya digunakan oleh petani di sawah untuk mengusir hama, utamanya burung, karena jaman dahulu tidak ada alat untuk mengusir hama. Selain itu juga karinding dimainkan di sawah sebagai simbol ucap syukur kepada Tuhan. 
Karinding yang digunakan dalam film ini bukan hanya digunakan di sawah, tapi bisa dimainkan dimana saja seperti di rumahnya Cakra. Fungsi karinding dalam film ini lebih kepada hiburan di tengah sawah ketika istirahat saat bertani, seperti dalam satu adegan ketika Cakra, Birawa dan Laksmi sedang beristirahat di saung lalu mereka bernyanyi diiringi karinding yang dimainkan oleh Cakra dan Birawa.

Selain seni musik karinding, kesenian yang ada yaitu seni vokal karena dialog disampaikan dengan cara dinyanyikan. Dalam film ini pula terdapat seni gerak yaitu seni tari yang terlihat pada akhir cerita. Ada dalam adegan ketika Birawa melihat Cakra dan Laksmi dari kejauhan, lalu warga menari di depan Cakra dan Laksmi. Birawa melihat mereka sembari memainkan karindingnya.

\section{SIMPULAN}

Film Cakra Buana karya sutradara Massimo Burhanuddin adalah sebuah film yang menggunakan bahasa dan latar budaya Sunda. Selain itu, film ini memiliki ciri khas karena dialog disampaikan dengan cara dinyanyikan. Maka dari itu, film ini diteliti unsur budayanya. Hasil analisis unsur budaya film ini meliputi, 1) bahasa, 2) sistem pengetahuan, 3) organisasi sosial, 4) sistem teknologi, 5) sistem mata pencaharian, 6), sistem religi, dan 7) kesenian.

Bahasa yang digunakan dalam film ini adalah bahasa Sunda. Ragam bahasa yang digunakan dalam dialog adalah bahasa loma, bahasa sedeng dan bahasa lemes (untuk orang lain). Sistem pengetahuan yang ditemukan dalam film ini adalah tentang alam sekitar, alam flora, zat bahan mentah dan benda-benda, tubuh manusia, sifat dan perilaku manusia, serta ruang dan waktu. Organisasi sosial yang ditemukan meliputi sistem pemerintahan, suksesi kepemimpinan, dan silsilah keluarga.
Sistem teknologi mencakup peralatan yang tergambar dalam adegan film, seperti peralatan produksi, dalam alat produksi meliputi peralatan potong, bertani, dan rumah tangga. Selain itu ada juga senjata dan wadah yang terbuat dari bambu dan kaleng.

Makanan dibagi berdasarkan bahan baku dan cara pengolahannya yang masih menggunakan cara tradisional. Pakaian yang digunakan oleh laki-laki yaitu iket, pangsi, kampret dan sarung, sedangkan perempuan mengenakan baju dan rok samping. Rumah atau bangunan yang ditemukan yaitu rumah panggung, balai desa, lumbung dan gubuk. Alat transportasi tidak terlalu diperlihatkan, hanya ada rakit.

Sistem mata pencaharian hanya satu yaitu pertanian. Sementara sistem keagamaan masih menggunakan konsep "Hyang", pengaruh dari Hindu dan Buddha. Lalu kesenian dalam film ini ada seni musik instrumental dan vokal, serta ada seni gerak yaitu seni tari yang ditampilkan di akhir cerita.

\section{UCAPAN TERIMA KASIH}

Puji dan syukur kami panjatkan kehadirat Allah SWT, atas rahmat-Nya artikel ini dapat terselesaikan. Peneliti juga mengucapkan terima kasih kepada berbagai pihak yang telah membantu. Semoga artikel ini bermanfaat bagi pembaca.

\section{CATATAN PENULIS}

Penulis menyatakan bahwa tidak ada konflik kepentingan terkait publikasi artikel ini. Penulis meng-konfirmasi bahwa data dan artikel ini bebas plagiarisme.

\section{PUSTAKA RUJUKAN}

Bungin, B. (2015). Analisis Data Penelitian Kualitatif. Jakarta: Rajawali Pers.

Ekadjati, E.S. (2014). Kebudayaan Sunda. Bandung: Pustaka Jaya. 
Halim, A. (2017). Makna Ornamen Pada Bangunan Candi Hindu dan Buddha di Pulau Jawa (Era Klasik Tua-Klasik Tengah-Klasik Muda). Jurnal RISA (Riset Arsitektur), 1, II, 170-191. doi: https://doi.org/10.26593/risa.v1i02. 2391.170-191.

Imanjaya, E. (2006). A to Z About Indonesian Film. Bandung: Mizan Bunaya Kreativa.

Isnendes, R. (2018). Menulis Skenario. Bandung: Departemen Pendidikan Bahasa Daerah.

Koentjaraningrat. (2009). Pengantar Ilmu Antropologi. Jakarta: Rineka Cipta.

Ratna, N.K. (2011). Teori, Metode, dan Teknik Penelitian Sastra. Yogyakarta: Pustaka Pelajar.

Sugiyono. (2013). Metode Penelitian Kuantitatif, Kualitatif dan $R \& D$. Bandung: Alfabeta.

Suherman A., Nugraha, H. S. (2018). Culture and Citizenship Literacy in Sundanese Children's Literature.
Dalam A. Gafar (Peny.) Prosiding $2^{\text {nd }}$ International Conference of Language, Literature, Culture, and Education (hlm. 456-461). Paris: Atlantis Press.

Suherman, A. (2019). Literacy Tradition of Sundanese Society - Indonesia: An annotation of the $16^{\text {th }}$ Century Ancient Manuscript. IJIER International Journal of Innovation of Education and Research, 7 (3), hlm. 262-271.

Sumardjo, J. (2011). Sunda: Pola Rasionalitas Budaya. Bandung: Kelir.

Tanpa nama. (2011, 20 Desember). "Budaya Sunda Jarang Diangkat di Film". Diakses dari https://www.beritasatu.com/budaya /22321-budaya-sunda-jarangdiangkat-di-film.html.

Triyanto. (2014). Pendidikan Seni Berbasis Budaya. Imajinasi: Jurnal Seni, VII, I, 33-42. https://journal.unnes.ac.id/. 